\title{
THE CONCEPT AND CONTENT OF PROPERTY RIGHTS OF CITIZENS
}

\author{
Teymuraz L. Pagava \\ Volgograd Institute of Management - Branch of the Russian Presidential Academy of National Economy \\ and Public Administration, Volgograd, Russian Federation
}

Introduction: in the article the author conducts a theoretical analysis of the institute of property rights in Russia. Evaluation of the category of "property rights" led to realizing the lack of not only the legal, but also the correct doctrinal definition of this concept. The studied approaches to the definition of the concept of "property rights", including the analysis of foreign normative legal acts, allowed determining the qualitative characteristics of this category and formulating the author's definition, claiming the legal consolidation. The research conducted by the author is based not only on the legislation of Russia, but also on the analysis of the legislation of other countries for determining the qualitative characteristics of this concept, which will allow formulating a correct definition. In this regard, the author aims to investigate the issue of the qualitative features of the concept of "property rights" and to formulate the definition that allows determining the role of this category in the civil law system of Russia. Methods: the methodological framework for this study is a set of methods such as the historical and legal, system methods, analysis, and the comparative law method. Results: as part of the study the point of view developed by the author is based on the analysis of not only the normative legal acts of Russia, but also the legislation of Armenia and the Republic of Kazakhstan, the civil scientists' opinion, as well as the existing judicial practice. The main emphasis in the research is on property rights as a concept in the civil law of Russia and the citizen as an authorized person. Conclusions: the study identified the following features inherent in the concept of "property right". These are: independence, alienation and availability of the right's monetary value. This led to the possibility of formulating the definition for the concept.

Key words: property, property rights, citizen, independence, alienation, monetary value.

Citation. Pagava T.L. The Concept and Content of Property Rights of Citizens. Legal Concept, 2019, vol. 18, no. 1, pp. 131-136. (in Russian). DOI: https://doi.org/10.15688/lc.jvolsu.2019.1.18

\section{ПОНЯТИЕ И СОДЕРЖАНИЕ ИМУЩЕСТВЕННЫХ ПРАВ ГРАЖДАН}

\author{
Теймураз Леванович Пагава \\ Волгоградский институт управления - филиал Российской академии народного хозяйства \\ и государственной службы при Президенте РФ, г. Волгоград, Российская Федерация
}

Введение: в статье автором проводится теоретический анализ института имущественных прав в России. Оценка категории «имущественные права» привела к осознанию отсутствия не только легального, но и корректного доктринального определения данного понятия. Исследование подходов к определению понятия «имущественные права», в том числе анализ нормативно-правовых актов иностранных государств, позволило определить качественные признаки данной категории и сформулировать авторское определение, претендующее на легальное закрепление.В связи с этим автором поставлена цель - исследовать вопрос о качеесто данной категории в системе гражданского права России. Методы: методологическую основу тивно-правовых актов не только Российской Федерации, но и Республики Армения и Республики Казахстан, 
мнений ученых-цивилистов, а также сложившейся судебной практики. Основной акцент в данной работе делается на имущественные права как понятие в гражданском праве России и гражданина - как управомоченного субъекта. Выводы: в ходе исследования были определены следующие признаки, свойственные понятию «имущественное право»: самостоятельность, отчуждаемость и наличие денежной оценки права, что позволило сформулировать определение данного понятия.

Ключевые слова: имущество, имущественные права, гражданин, самостоятельность, отчуждаемость, денежная оценка.

Цитирование. Пагава Т. Л. Понятие и содержание имущественных прав граждан // Legal Concept $=$ Правовая парадигма. - 2019. - Т. 18, № 1. - C. 131-136. - DOI: https://doi.org/10.15688/lc.jvolsu.2019.1.18

\section{Введение}

С принятием в 1994 г. части I Гражданского кодекса РФ (далее - ГК РФ) перед государством была поставлена задача - обеспечить правовое регулирование имущественных отношений, которые на тот момент складывались в обществе. И несмотря на то что прошло более 25 лет, законодатель до сих пор не дал легального определения понятию «имущественные права». В связи с этим как в научной мысли, так и в правоприменительной практике остается актуальным вопрос: что такое имущественные права?

В защиту законодателя стоит отметить, что попытки выделить имущественные права на фоне других прав предпринимались. К примеру, ст. 128 ГК РФ в качестве объектов гражданских прав именует имущественные права [3]. Однако указанный перечень не содержит легального определения данного понятия, что не позволяет однозначно ответить, какие права могут считаться имущественными. В качестве другого примера можно отметить ст. 132 ГК РФ, содержащую перечень имущества, входящего в состав предприятия. Но данный перечень предусмотрен для конкретного участника гражданских правоотношений - юридического лица с указанием на вид осуществляемой им деятельности.

\section{Имущественные права граждан}

В ГК РФ категория «имущественные права» встречается не раз, однако легального определения в данных случаях также не предусмотрено. Попытки Конституционного Суда РФ в своих Постановлениях от 28 окрября 1999 г. № 14-П и от 06 июня 2000 г. № 9-П не способствовали решению данной проблемы.
Например, в Постановлении Конституционного Суда РФ от 28 октября 1999 г. № 14-П имущественные права отождествляются с правами требования, что вытекает из содержания абз. 2 п. 2 указанного постановления [8]. Подобная позиция также имеет свою поддержку в научном мире. Так, В.К. Андреев считает, что имущественные права тождественны правам требования. В обосновании данной позиции приводится ссылка на ст. 336 ГК РФ, где имущественные права выступают предметом залога [1, с. 29]. В таком случае возникает вопpoc: возможно ли ограничиться только правом требования в имущественных отношениях? Если да, то в таком случае исключительные права и правоотношения, вытекающие из обязательств и наследования, по мнению В.К. Андреева и Конституционного Суда РФ, не могут быть признаны имущественными, что само по себе является противоречивым. Аналогичной позиции придерживается и А.Н. Лысенко, по мнению которого подобное упоминание подтверждает позицию о вычленении из всего объема имущественных прав права требования [6, с. 91].

В дальнейшем в Постановлении Конституционного Суда РФ от 6 июня 2000 г. № 9-П имущественные права стали рассматриваться неразрывно с другим термином - «имущество», в состав которого включается всякое имущество, имеющее связь с осуществлением права частной и иной формы собственности, а также имущественные права, если эти имущественные права принадлежат лицу на законных основаниях [9]. Однако и данный подход не является верным, ибо в термине «имущественные права» присутствует слово «имущество», а определить «имущественные» через «имущество» невозможно.

В Республике Казахстан уже имеется попытка дать легальное определение имуще- 
ственных прав. Так, согласно п. 23 ст. 1 Закона Республики Казахстан от 1 марта 2011 г. № 413-IV «O государственном имуществе», имущественные права государства - права государства на имущество, включающие в себя: 1) право государственной собственности; 2) иные вещные права государства (сервитут, аренда, безвозмездное пользование имуществом и др.); 3) обязательственные права (права требования) государства; 4) исключительные права на объекты интеллектуальной собственности, принадлежащие государству; 5) наследственные права; 6) иные имущественные права государства, предусмотренные законами Республики Казахстан [5].

Однако остается нерешенным вопрос о качественной оценке данного определения, поскольку из него невозможно определить особенности или признаки, свойственные ему, а также необходимо отметить, что данное определение относится только к государству, а не ко всем участникам гражданского оборота.

Гражданский кодекс Республики Армения от 28 июля 1998 г. (далее - ГК РА) также содержит данную категорию. Однако легального определения в нем мы не находим, несмотря на то, что категория «имущественное право» рассматривается без учета конкретного субъекта гражданских правоотношений - государства, что позволяет сделать вывод о ее применении в том числе к физическим лицам. Сделанный вывод подтверждается наименованием раздела 4 ГК PA - «Право собственности и другие имущественные права», что однозначно говорит о включении данного права в комплекс прав, свойственных имущественным [2].

Также следует выделить Гражданский кодекс Нидерландов (далее - ГКН), а именно книгу 3. Так, в ст. 6 книги 3 ГКН под имущественными правами понимаются права, которые могут быть переданы отдельно или вместе с другим правом либо предназначены для предоставления материальной выгоды бенефициара или были приобретены в обмен на предоставленное или обещанное материальное преимущество [4]. Подход законодателя к формированию легального определения данной категории, без сомнения, выделяет его на фоне вышерассмотренных примеров. В данном определении имеются такие ключевые признаки, как:
1) «материальная выгода и преимущество». Этот признак может быть рассмотрен в качестве стоимостной оценки права. Его следует учесть при формировании легального определения;

2) «передача имущественного права либо вместе с другим правом, либо в отдельности». Данный признак следует применять только с учетом особенностей отдельных имущественных прав, поскольку в случае передачи вещного права имущественные права на него также переходят к новому собственнику, в отличие от обязательственного права, где отношения возникают между субъектами, а не между субъектом и вещью.

Подход голландского законодателя, по нашему мнению, отличается теоретической обоснованностью и практической целесообразностью, так как это позволяет сформулировать конкретный перечень имущественных прав, которые будут рассмотрены позже. В связи с этим следует определить признаки имущественных прав, позволяющие выделить данную категорию в гражданском праве на фоне других, тем самым предусмотреть критерии отнесения тех или иных прав к имущественным.

Так, для формирования определения B.А. Шириев предлагает выделить 3 признака, свойственные имущественным правам, [10, с. 109].

Первый признак - самостоятельность. Данный признак трактуется следующим образом: имущественное право рассматривается как объект гражданского права в его чистом виде при условии возникновения способности существовать независимо от других объектов, то есть представляет самостоятельную ценность. Также следует отметить, что самостоятельностью обладает и неимущественное право. Данный признак может быть включен в определение, но не как исключительный, определяющий его специфику и сущность.

Второй признак - отчуждаемость. Этот признак исследует возможность имущественных прав изолироваться от своего носителя, что приводит к свободному функционированию в гражданском обороте этих объектов. С данным доводом нельзя согласиться, поскольку имеются правоотношения, которые 
непосредственно связаны с личностью субъектов и не могут быть отчуждаемы. Примером таких имущественных прав является право на пенсионное обеспечение как разновидность имущественных социальных прав. Данное право возникает у лица по достижении определенного возраста и при наличии предусмотренного стажа. Поскольку оно тесно связано с личностью, то не может быть передано иным лицам. Из этого следует вывод, что данный признак также не является исключительным, а может применяться только к отдельным правоотношениям (в рамках института вещного права).

Третий признак - наличие денежной оценки права. Он представляет собой позицию, в силу которой имущественные права, а также любые имущественные объекты обязаны быть приспособлены к гражданскому обороту и возмездному обмену. По этой причине они обязаны иметь определенную ценность и обладать стоимостной оценкой. С данным признаком можно согласиться, при этом следует отметить, что он является ключевым для определения права как имущественного. Стоимостная оценка имущественного права позволяет выделить его на фоне других прав, тем самым закрепляя его место в гражданских правоотношениях.

Исследуя вопрос содержания имущественных прав, необходимо отметить, что стандартное разделение данной категории на субъективное право и субъективную обязанность, как в гражданских правоотношениях, недопустимо. Поскольку право само по себе не может выступать обязанностью, несмотря на то, что право одного лица априори порождает обязанность другого лица по отношению к нему, имущественное право - это в первую очередь субъективное право, следовательно данной категории свойственен только один элемент гражданского правоотношения.

Под субъективным правом, в рамках имущественных прав, следует понимать правомочие лица по совершению действий, направленных в отношении материального или нематериального блага, имеющего стоимостную оценку, с целью удовлетворения внутренних потребностей указанного лица. Поскольку имущественное субъективное право неразрывно связано с субъектом гражданс- ких прав, с учетом заявленной автором темы исследования необходимо обратить особое внимание на субъектный состав - на граждан как участников гражданского оборота.

Ст. 9 ГК РФ предусматривает, что граждане и юридические лица по своему усмотрению осуществляют принадлежащие им гражданские права, однако не стоит списывать со счетов государство и его органы и организации, а также органы местного самоуправления, которые хотя и поименованы в данной статье, также выступают субъектом гражданских правоотношений [3]. При анализе имущественных правоотношений следует отметить, что как физическое лицо, так и юридическое лицо, и тем более государство и органы местного самоуправления, являются субъектами, выступающими в имущественных правоотношениях.

Ст. 35 Конституции РФ провозгласила право каждого лица иметь имущество в собственности, владеть, пользоваться и распоряжаться им как единолично, так и совместно с другими лицами. Из этого следует, что имущественные права, порождаемые материальным и нематериальным благом, возникают у любого субъекта гражданских правоотношений независимо от правового статуса субъекта.

Обращая внимание на гражданина, положения ГК РФ устанавливают отдельные критерии, которым должно соответствовать лицо для реализации своих прав.

Первым критерием является достижение определенного возраста. При этом мною отмечается именно такая формулировка, как возрастное соответствие, а не совершеннолетие, поскольку, достигая возраста 14 лет, лицо приобретает возможность самостоятельно, без согласия родителей совершать как мелкие бытовые сделки, так и распоряжаться собственными доходами и при этом нести персональную имущественную ответственность за совершенные действия. Как видно, возрастной ценз играет немаловажную роль в формировании имущественной самостоятельности у физических лиц.

Вторым критерием является полная или, в отдельных случаях, ограниченная дееспособность. Полная дееспособность позволяет субъекту реализовывать свое имущественное 
право без ограничений в тех случаях, когда законом не предусмотрен особый порядок реализации имущественного права (например, государственная регистрация прав при передаче недвижимого имущества при совершении купли-продажи указанного объекта, предусмотренная ст. 551 ГК РФ). При ограниченной дееспособности за гражданином сохраняется право самостоятельно совершать мелкие бытовые сделки, и только по этим сделкам он несет имущественную ответственность самостоятельно. В остальных случаях такое лицо вправе совершать сделки лишь с согласия попечителя. Однако указанное лицо несет персональную имущественную ответственность за совершенные им сделки, а также за причиненный им вред.

В связи с этим можно сделать вывод, что при соответствии гражданина данным критериям у лица возникает правомочие по реализации имущественных прав. Существование имущественных прав в качестве самостоятельных объектов гражданских правоотношений обусловлено не только потребностями гражданского оборота. На практике предметом сделок все чаще становятся права по договорам аренды, поставки, требования по денежным обязательствам, компенсациям и выплатам и др. [7].

\section{Выводы}

Таким образом, завершая исследование понятия и содержания имущественных прав граждан, можно сделать следующий вывод.

Имущественные права гражданина - это права, возникающие по основаниям, предусмотренным законом, охраняемые государством, подлежащие оценке правомочия физического лица: 1) владеть, пользоваться, распоряжаться определенными вещами; 2) требовать от других лиц совершения определенных действий по передаче имущества, выполнению работ, оказанию услуг; 3) воздерживаться от определенных действий, которые могут нанести имущественный ущерб или воспрепятствовать получению выгоды.

Данное определение может быть использовано законодателем для определения такой категории гражданского права, как имущественные права граждан.

\section{СПИСОК ЛИТЕРАТУРЫ}

1. Андреев, В. К. Рынок ценных бумаг. Правовое регулирование : курс лекций / В. К. Андреев. - М. : Юрид. лит., 1998. - 151 с.

2. Гражданский кодекс Республики Армении от 28 июля 1998 г. № ЗР-239 : (ред. от 07.07.2016 № 3Р-115) // Официальные ведомости Республики Армения. - 1998. - № 17 (55).

3. Гражданский кодекс Российской Федерации от 30 ноября 1994 года № 51-Ф3 : (ред. от 07.02.2017 № 12-Ф3) // Российская газета. - 1994. - № 238/239.

4. Гражданский кодекс Нидерландов. Книга 3. - Электрон. текстовые дан. - Режим доступа: http://wetten.overheid.nl/BWBR0005291/2017-09-01 (дата обращения: 25.10.2018). - Загл. с экрана.

5. Закон Республики Казахстан от 1 марта 2011 г. № 413-IV «О государственном имуществе» : (ред. от 25.12.2017 № 122-VI) // Ведомости Парламента РК. - 2011. - № 5 (2582). - Ст. 42.

6. Лысенко, А. Н. Понятие и виды имущества в гражданском праве России : дис. ... канд. юрид. наук / Лысенко Александр Николаевич. - Самара, 2007. $-233 \mathrm{c}$.

7. Постановление Арбитражного суда Московского округа от 25 апреля 2016 г. № Ф05-2889/2016 по делу № A40-57347/15. - Электрон. текстовые дан. Режим доступа: http://pravosudie.biz/897626 (дата обращения: 25.10.2018). - Загл. с экрана.

8. Постановление Конституционного Суда РФ от 28 октября 1999 г. № 14-П «По делу о проверке конституционности статьи 2 Федерального закона “О внесении изменений и дополнений в Закон Российской Федерации "О налоге на прибыль предприятий и организаций” в связи с жалобой ОАО “Энергомашбанк”». - Доступ из справ.-правовой системы «КонсультантПлюс».

9. Постановление Конституционного Суда РФ от 6 июня 2000 г. № 9-П «По делу о проверке конституционности положения абзаца третьего пункта 2 статьи 77 Федерального закона “О несостоятельности (банкротстве)” в связи с жалобой открытого акционерного общества "Тверская прядильная фабрика"». - Доступ из справ.-правовой системы «КонсультантПлюс».

10. Шириев, В. А. Имущественные права: проблемы нормативной модели / В. А. Ширяев // Пробелы в российском законодательстве. - 2010. - № 3. C. 108-111.

\section{REFERENCES}

1. Andreev V.K. Rynok tsennykh bumag. Pravovoe regulirovanie. Kurs lektsiy [Securities Market. Legal Regulation. Lecture Course]. Moscow, Yuridicheskaya literatura, 1998. $151 \mathrm{p}$. 
2. Grazhdanskiy kodeks Respubliki Armenii ot 28 iyulya 1998 goda № ZR-239 (v red. ot 07.07.2016 № ZR-115) [Civil Code of the Republic of Armenia dated July 28, 1998 No. ZR-239 (as amended on 07/07/ 2016 No. ZR-115)]. Ofitsialnye vedomosti Respubliki Armeniya [Official Gazette of the Republic of Armenia], 1998, no. 17 (55).

3. Grazhdanskiy kodeks Rossiyskoy Federatsii ot 30 noyabrya 1994 goda № 51-FZ (v red. FZ ot 07.02.2017 № 12-FZ) [Civil Code of the Russian Federation of November 30, 1994 No. 51-FZ (as amended by theFederal Law of February 7, 2017 No. 12-Ф3)]. Rossiyskaya gazeta [Russian Newspaper], 1994, no. 238/239.

4. Grazhdanskiy kodeks Niderlandov. Kniga 3 [Civil Code of the Netherlands. Book 3]. URL: http:// wetten.overheid.n1/BWBR0005291/2017-09-01 (accessed 25 October 2018).

5. Zakon Respubliki Kazakhstan ot 1 marta 2011 goda № 413-IV «O gosudarstvennom imushchestve» (v red. Zakona RK ot 25.12.17 g. № 122-VI) [Law of the Republic of Kazakhstan dated March 1, 2011 No. 413-IV "On State Property" (as amended by the Law of the Republic of Kazakhstan dated December 25, 177 No. 122-VI)]. Vedomosti Parlamenta RK [Statements of the Parliament of the Republic of Kazakhstan], 2011, no. 5 (2582), art. 42 .

6. Lysenko A.N. Ponyatie $i$ vidy imushchestva v grazhdanskom prave Rossii: dis. ... kand. yurid. nauk [The Concept and Types of Property in the Civil Law of Russia. Cand. jurid. sci. diss.]. Samara, 2007. 233 p.

7. Postanovlenie Arbitrazhnogo suda Moskovskogo okruga ot 25.04.2016 № F05-2889/2016 po delu № A40-57347/15 [Resolution of the Arbitration Court of the Moscow District of April 25, 2016 No. F05-2889/2016 in Case No. A40-57347/15].
Access from Reference Legal Sistem 'Consultant Plus' (accessed 25 October 2018).

8. Postanovlenie Konstitutsionnogo suda RF ot 28.10 .1999 g. № 14-P «Po delu o proverke konstitutsionnosti stati 2 Federalnogo zakona "O vnesenii izmeneniy i dopolneniy v Zakon Rossiyskoy Federatsii " $O$ naloge na pribyl predpriyatiy $i$ organizatsiy" $v$ svyazi s zhaloboy OAO "Energomashbank"» [Resolution of the Constitutional Court of the Russian Federation ofOctober 28, 1999 No. 14-P "On the Case of Verifying the Constitutionality of Article 2 of the Federal Law on Amendments and Additions to the Law of the Russian Federation" On Profit Tax ofEnterprises and Organizations "In Connection with the Complaint of Energomashbank"]. Access from Reference Legal Sistem 'Consultant Plus'.

9. Postanovlenie Konstitutsionnogo suda RF ot 06.06 .2000 g. № 9-P «Po delu o proverke konstitutsionnosti polozheniya abzatsa tretego punkta 2 stati 77 Federalnogo zakona "O nesostoyatelnosti (bankrotstve)" v svyazi s zhaloboy otkrytogo aktsionernogo obshchestva "Tverskaya pryadilnaya fabrika" " [Resolution of the Constitutional Court of the Russian Federation of 06.06.2000 No. 9-P "On the Case of Verifying the Constitutionality of the Provision of the Third Paragraph of Paragraph 2 of Article 77 of the Federal Law "On Insolvency (Bankruptcy)" in Connection with the Complaint of the Tver Spinning Factory Open Joint-Stock Company"]. Access from Reference Legal Sistem 'Consultant Plus'.

10. Shiriev V.A. Imushchestvennye prava: problemy normativnoy modeli [Property Rights: Problems of the Regulatory Model]. Probely $v$ rossiyskom zakonodatelstve [Gaps in the Russian Legislation], 2010, no. 3, pp. 108-111.

\section{Information about the Author}

Teymuraz L. Pagava, Postgraduate Student, Department of Civil Law Disciplines, Volgograd Institute of Management - Branch of the Russian Presidential Academy of National Economy and Public Administration, Gagarina St., 8, 400131 Volgograd, Russian Federation, teymuraz94@rambler.ru, https://orcid.org/0000-0003-2199-3278

\section{Информация об авторе}

Теймураз Леванович Пагава, аспирант кафедры гражданско-правовых дисциплин, Волгоградский институт управления - филиал Российской академии народного хозяйства и государственной службы при Президенте РФ, ул. Гагарина, 8, 400131 г. Волгоград, Российская Федерация, teymuraz94@rambler.ru, https://orcid.org/0000-0003-2199-3278 